\title{
Reference Values for Some Hematological Parameters in Iraqi Local Horses
}

\author{
Hayder Dawood Saleem and Firas Rashad Al-Samarai* \\ Department of Veterinary Public Health, University of Baghdad, Iraq
}

\begin{abstract}
A cross-sectional study was conducted to determine some hematological values in Iraqi local horses in order to increase the precision of diagnosis particularly no published data existed about this subject in Iraq. A total of 126 blood samples were collected from the jugular vein of horses randomly from several regions in the Middle and South of Iraq during the period from February to December 2017. The age of horses ranged from 2-17 year for both sexes ( 33 male and 93 female). Reference value adviser was used to estimates these parameters. Results revealed that the local reference intervals (LRI) as following: The red blood cell count (RBC) (5.61-7.90×106 $\mu \mathrm{l})$, hemoglobin (Hb) (8.42$12.10 \mathrm{~g} / \mathrm{dL}$ ), packed cell volume (PCV) (23.86-33.12\%), corpuscular hemoglobin concentration (MCHC) (32.40-41.30g/ dl), corpuscular hemoglobin (MCH) (14.90-16.90pg), corpuscular volume (MCV) (38.90-52.00fl), and white blood cells (WBC) $\left(6.78-12.79 \times 10^{3} \mu \mathrm{l}\right)$. The results showed that the lower limit of the LRI was lowered than the lower limit of the general reference intervals (GRI) for each of RBC, $\mathrm{Hb}$, and PCV, while the lower limit of the LRI in the others parameters are within the range of the GI. The results obtained from statistical analysis confirmed that the effect of age was not significant, but the effect of sex was significant $(\mathrm{P}<0.05)$ only on PCV and Hb. The mean value of males was significantly $(\mathrm{P}<0.05)$ higher than females. In conclusion, the results of the LRI showed substantial differences as compared with the GRI and this will increase the need for establishing reference values for horses as well as for all local animals.
\end{abstract}

KEYWORDS: Reference values; Hematological parameters; Reference value advisor; Iraqi local horses

ABBREVIATIONS: Hb: Hemoglobin; RBC: Red Blood Cells; PCV: Packed Cell Volume; WBC: White Blood Cell; MCV: Mean Corpuscular Volume; MCH: Mean Corpuscular Hemoglobin; MCHC: Mean Corpuscular Hemoglobin Concentration; RI: Reference Interval; LSD: Least Significant Difference; LRI: Local Horse Reference Intervals; GRI: General Reference Intervals

\section{INTRODUCTION}

The evaluating and monitoring the health status, the nutritional level and metabolic conditions of the animals can be performed based on the blood parameters profile [1].

The importance of the reference values lies in its role in the decision-making process related to the health status of the animal [2]. However, numerous studies confirmed that the hematological parameters influenced by some factors for instance: age, gender, breed, level of nutrition, type of activity and physiological status [3-6] this will not reduce its importance in the monitoring of the health, nutritional, and therapeutic status of horses.

The physical fitness and performance of horses depend on their health status, thus to achieve a high performance, it is very
Quick Response Code:

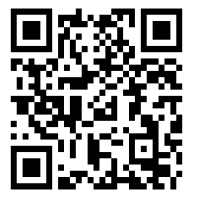

Address for correspondence: Firas Rashad Al-Samarai, Department of Veterinary Public Health, College of Veterinary Medicine, University of Baghdad, Iraq

Received: November 16, 2019 Published: December 19, 2019

How to cite this article: Hayder Dawood S, Firas Rashad Al-S. Reference Values for Some Hematological Parameters in Iraqi Local Horses. 2019 - 1(3) OAJBS.ID.000129. DOI: $10.38125 /$ OAJBS.000129 
important to maintain and control the health status of horses and this can be done by using reliable tools such as hematological parameters [6]. Several studies conducted to investigate the effect of age and gender on the reference values: for instance, Lana found a statistically significant effect of sex on $\mathrm{Hb}$ whereas no significant difference associated with age was detected in the Croatian cold blood horses. The significant high values of $\mathrm{Hb}$ and PCV are common in males [7] This could be attributed to the effect of androgens on erythropoiesis [8]. Similar results were obtained by Gordon et al., 2007 who reported that the variations in PCV according to age and gender were significant. On the other hand, Tomenendalova et al. [5]; Cruz et al. [9] confirmed the non-significant effect of age and gender on the $\mathrm{Hb}, \mathrm{PCV}, \mathrm{RBC}, \mathrm{MCHC}$, and $\mathrm{WBC}$ in horses.

The reference values of Iraqi local horses are nearly completely lacking. Moreover, a few researches have been conducted in Iraq included a small sample size $[10,11]$, therefore, the reliability of these estimations was very low beside the estimations were limited to just of the range or/and the mean of the hematological parameters and this led to an inaccurate estimations as compared with the percentile confidence interval of LRI. Hence, this study was carried out to establishing reference values of Iraqi horses to be a useful guide for veterinarians to monitor the health status of animals along with to investigate the effect of age and gender on studied parameters.

\section{MATERIALS AND METHODS}

\section{Study Design}

A cross-section study was conducted on Iraqi local horses during the period from February to December 2017. The area of the survey included Baghdad, Waset, Al-Dewanai, Diyala, Babylon, AL-Najaf, Karbala and AL-Nasiriyah. The age of horses ranged from 2-17 year for both sex.

\section{Animals}

A total of 126 clinically healthy Iraqi local horses (33 male and 93 female) were selected randomly. In the sampling day, the breeders have been asked some questions about the current and past health status, sexual status, medications after that all animals subjected to complete physical examinations which were performed by an experienced veterinarian to ensure the health status.

\section{Blood Samples}

The blood sample $(5 \mathrm{ml})$ was drawn from the jugular vein after sterilizing the puncture area with $70 \%$ alcohol using disposable syringes. Blood samples were placed into labeled sterile tubes containing anti-coagulant (EDTA) and kept at $4{ }^{\circ} \mathrm{C}$ for hematological analyses which were performed within the next $24 \mathrm{~h}$. The blood samples were analyzed in the laboratory of the College of Veterinary Medicine/University of Baghdad/Iraq.

\section{Hematological Parameters}

The parameters used in the current study included: the red blood cells (RBC), packed cell volume (PCV), hemoglobin ( $\mathrm{Hb}$ ), white blood cell count(WBC), mean corpuscular volume (MCV), mean corpuscular hemoglobin (MCH), and mean corpuscular hemoglobin concentration (MCHC). The MCV, MCH, and MCHC were calculated according to Patterson et al. [12].

\section{Statistical Analysis}

The International Federation of Clinical Chemistry (IFCC) 1987 recommended using not less than 120 animals to determine the population-based reference interval (RI). Hence, data of 126 local horses were subjected to analysis to determine the reference values by using Reference Values Advisor V 2.1.

The data were analyzed by using SAS [13] to investigate the effect of the age and gender of the animal using the following mathematical model:

$$
Y_{i j k}=\mu+A_{i}+G_{j}+e_{i j k}
$$

Where:

$\mathrm{Y}_{\mathrm{ijk}}$ is the studied trait

$\mu$ is the overall means

$A_{i}$ the effect of $i^{\text {th }}$ age $(i=\leq 3,>3-6,>6-10,>10)$

$\mathrm{Gj}$ the effect of $\mathrm{j}^{\text {th }} \operatorname{sex}(\mathrm{j}=$ male, female $)$

$\mathrm{e}_{\mathrm{ijk}}$ is the random error

Means were compared using the least significant difference (LSD). $\mathrm{P}<0.05$ is considered statistically significant. Because there was a significant difference in $\mathrm{Hb}$ and PCV between males and females, the data were analyzed to estimate the reference interval for the two parameters of each sex.

\section{RESULTS}

Table 1: The reference intervals of some hematological parameters in clinically healthy Iraqi local horses estimated by the reference value advisor.

\begin{tabular}{|c|c|c|c|c|c|c|c|c|c|c|}
\hline Parameter & Unit & Mean & Median & SD & Lower limit RI & $\mathrm{LL}\left(\mathrm{CI}_{\mathbf{9 0} \%}\right)$ & $\begin{array}{c}\text { Upper } \\
\text { limit RI }\end{array}$ & $\mathrm{UL}\left(\mathrm{CI}_{90 \%}\right)$ & Method & GRI \\
\hline $\mathrm{RBC}$ & $\mathrm{x} 10^{6}$ & 6.52 & 6.4 & 0.57 & 5.61 & $(5.51-5.77)$ & 7.9 & $(7.83-7.90)$ & NP & $6.8-12.9$ \\
\hline $\mathrm{Hb}$ & $\mathrm{g} / \mathrm{dL}$ & 10.24 & 10.2 & 0.89 & 8.42 & $(8.20-8.70)$ & 12.1 & $(12.00-12.10)$ & NP & 19-Nov \\
\hline PCV & $\%$ & 28.49 & 28.3 & 2.33 & 23.86 & $23.33-24.42$ & 33.12 & $32.52-33.69$ & S & $32-53$ \\
\hline MCHC & $\mathrm{g} / \mathrm{dl}$ & 36.62 & 35.95 & 2.67 & 32.4 & $(23.40-33.00)$ & 41.3 & $(41.20-42.00)$ & NP & $31.0-38.6$ \\
\hline $\mathrm{MCH}$ & pg & 15.89 & 15.9 & 0.54 & 14.9 & $(14.80-1510)$ & 16.9 & $(16.80-17.10)$ & NP & $12.3-19.7$ \\
\hline MCV & $\mathrm{fl}$ & 43.98 & 44.3 & 3.82 & 38.9 & $(38.90-38.90)$ & 52 & $(51.00-54.00)$ & NP & $37-59$ \\
\hline WBC & $\mathrm{x} 10^{3}$ & 9.78 & 9.85 & 1.51 & 6.78 & $(6.43-7.14)$ & 12.79 & $(12.41-13.15)$ & S & $5.4-14.3$ \\
\hline
\end{tabular}

GRI: General reference values (Constable et al., 2016)

NP: Non-parametric method

S: Standard method 

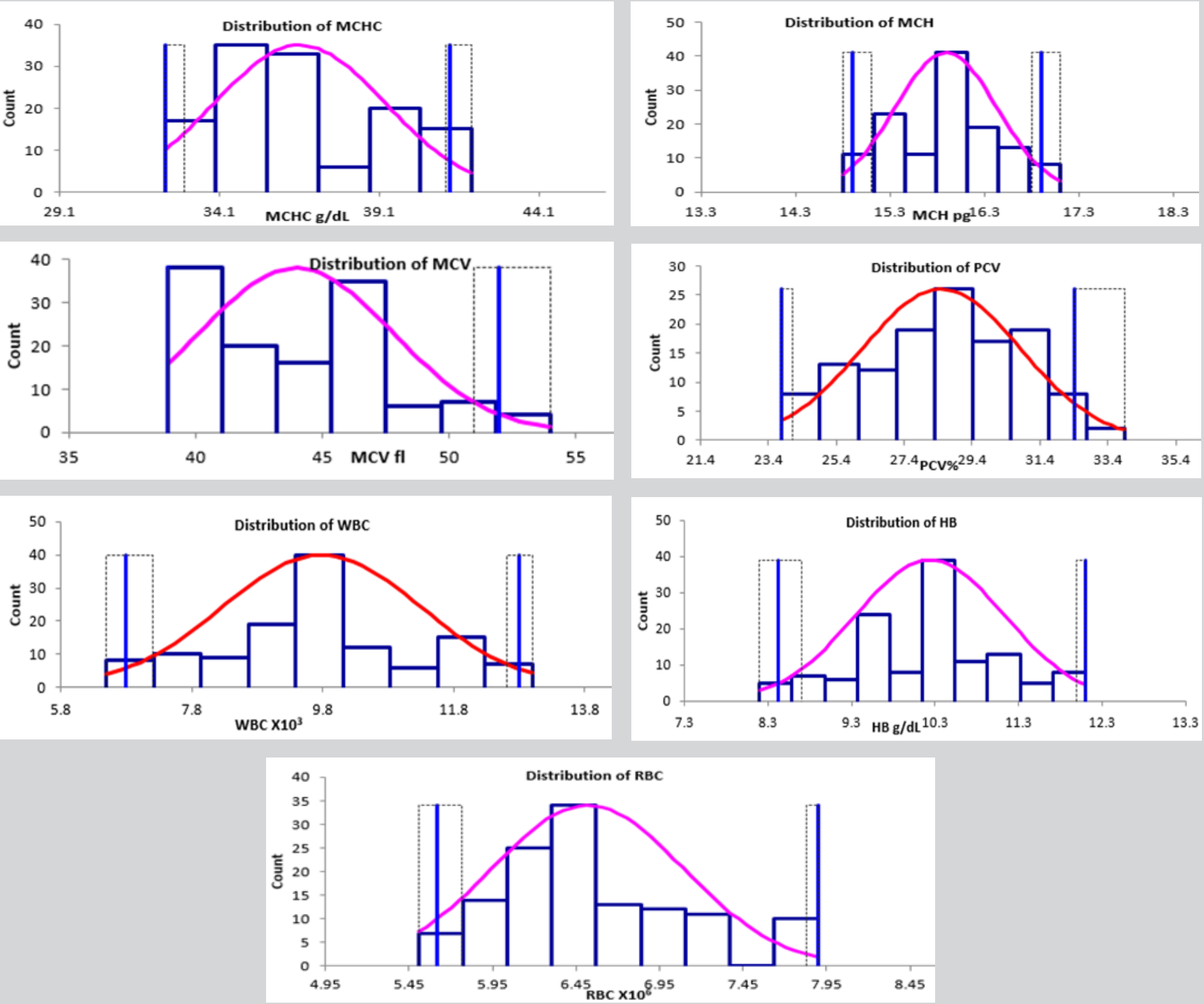

Figure 1: Distributions of observed (blue boxes) and fitted (purple lines) curves of some hematological parameters of 126 clinically healthy Iraqi local horses. Blue vertical lines are the reference limits with corresponding $90 \%$ confidence intervals as the dotted line. Graphs with purple curve were not normally distributed whereas graphs with the red curve are normally distributed.

The results of hematological local horse reference intervals (LRI) are shown in Table 1 which was also illustrated the general reference intervals (GRI) [14]. The distribution of all parameters is shown in the Figure 1. The data of PCV and WBC were normally distributed; therefore, we have selected the standard method for the estimation of the reference values (Figure 1). The distribution of the data of the others parameters did not follow the normal distribution and the test of Anderson-Darling confirmed that the standard, Box-Cox standard, Robust, and Robust Box-Cox are not suitable for estimation reference values, thus in such case the nonparametric test is the last solution. The 95\% Lower and Upper limit of $\mathrm{Hb}$ in Iraqi horses $(8.42-12.10 \mathrm{~g} / \mathrm{dl})$ are lowest than the corresponding estimations of the GRI [3,4,7,11-13,15-17]. The situation is the same in PCV (23.86-33.12\%) and RBC (5.61-7.90x $10^{6}$ ). The corresponding estimations of the GRI are $32-53 \%$ and $6.8-12.9 \times 10^{6}$. Concerning to the estimations of the MCV (38.90$52.00 \mathrm{fl}), \mathrm{MCH}(14.90-16.90 \mathrm{pg})$ and WBC $\left(6.78-12.79 \times 10^{3}\right)$, these estimations are within the range of GRI. For the MCHC (32.40-41.30 $\mathrm{g} / \mathrm{dl}$ ) the upper limit was higher than the upper limit of the both GRI.
The statistical analysis showed no significant effect of age on all parameters (Table 2), whereas the effect of sex was significant $(\mathrm{P}<0.05)$ on $\mathrm{PCV}$ and $\mathrm{Hb}$ (Table 3$)$. The estimations in males $(28.84 \%, 10.48 \mathrm{~g} / \mathrm{dl})$ were higher than females $(27.20 \%, 10.01 \mathrm{~g} /$ dl). Hence, the data of males and females were subjected to analysis to establish reference values of $\mathrm{Hb}$ and PCV for each sex (Table 4). The lower and upper RI of male was $8.39-12.37 \mathrm{~g} / \mathrm{dL}$ and 22.69$38.18 \%$ for $\mathrm{Hb}$ and PCV respectively while the corresponding estimations in females were $7.20-12.10 \mathrm{~g} / \mathrm{dL}$ and $17.65-33.31 \%$.

\section{DISCUSSION}

Despite the importance of hematological reference values of equines, there are a few reports of Iraqi local horses which were published, and the estimations of values are usually presented as the range (lowest and highest values) or as the mean \pm standard deviation. Thus, this research represents in our knowledge the first work to establish the reference values for Iraqi local horses which are virtually absent in Iraq. The determination of the reference values was performed using reference value advisor and the values 
were presented as lower and upper limits. Therefore, these values will be more accurate for Iraqi local horses than the previously published values presented as mean and range and more suitable than the general reference values because these values reflect the real values of Iraqi local horse under Iraqi local environment.
However, the reference values of Iraqi local sheep [18] and goats [19] using reference values adviser were published recently, but there is a lack of reference values for the most Iraqi local animals such as cows, buffaloes, camels, and donkeys along with all the poultry.

Table 2: The effect of age on some hematological parameters in Iraqi local horses.

\begin{tabular}{|c|c|c|c|c|c|c|c|c|}
\hline Age/yr. & No & $\mathbf{R B C x} \mathbf{1 0}^{\mathbf{6}}$ & $\mathbf{P C V} \%$ & $\mathbf{H b} \mathbf{g} / \mathbf{d l}$ & $\mathbf{M C V} \mathbf{f l}$ & $\mathbf{M C H} \mathbf{~ p g}$ & $\mathbf{M C H C} \mathbf{g} / \mathbf{d} \mathbf{~}$ & $\mathbf{W B C x} 10^{3}$ \\
\hline$\leq 3$ & 20 & $6.35 \pm 0.17$ & $27.78 \pm 0.67$ & $10.26 \pm 0.26$ & $44.41 \pm 0.86$ & $15.84 \pm 0.13$ & $36.14 \pm 0.58$ & $9.23 \pm 0.41$ \\
\hline$>3-6$ & 30 & $6.24 \pm 0.17$ & $26.68 \pm 0.89$ & $9.80 \pm 0.26$ & $43.61 \pm 0.69$ & $15.91 \pm 0.08$ & $37.01 \pm 0.47$ & $9.96 \pm 0.27$ \\
\hline$>6-10$ & 39 & $6.52 \pm 0.13$ & $28.16 \pm 0.67$ & $10.37 \pm 0.18$ & $44.34 \pm 0.62$ & $15.92 \pm 0.08$ & $36.22 \pm 0.44$ & $9.54 \pm 0.28$ \\
\hline$>10$ & 37 & $6.36 \pm 0.10$ & $27.75 \pm 0.71$ & $10.08 \pm 0.14$ & $43.64 \pm 0.63$ & $15.88 \pm 0.09$ & $36.95 \pm 0.43$ & $9.93 \pm 0.30$ \\
\hline
\end{tabular}

All differences are not significant

Table 3: The effect of gender on some hematological parameters in Iraqi local horses.

\begin{tabular}{|c|c|c|c|c|c|c|c|c|}
\hline Sex & No & $\mathbf{R B C x} \mathbf{1 0}^{\mathbf{6}}$ & $\mathbf{P C V} \%$ & $\mathbf{H b} \mathbf{g} / \mathbf{d l}$ & $\mathbf{M C V} \mathbf{f l}$ & $\mathbf{M C H} \mathbf{~ p g}$ & $\mathbf{M C H C} \mathbf{g} / \mathbf{d l}$ & $\mathbf{W B C x} \mathbf{1 0}^{\mathbf{3}}$ \\
\hline Male & 33 & $6.53 \pm 0.11$ & $28.84 \pm 0.68 \mathrm{a}$ & $10.48 \pm 0.16 \mathrm{a}$ & $44.52 \pm 0.67$ & $15.81 \pm 0.09$ & $36.37 \pm 0.41$ & $9.79 \pm 0.32$ \\
\hline Female & 93 & $6.32 \pm 0.08$ & $27.20 \pm 0.42 \mathrm{~b}$ & $10.01 \pm 0.12 \mathrm{~b}$ & $43.78 \pm 0.39$ & $15.92 \pm 0.05$ & $36.70 \pm 0.28$ & $9.68 \pm 0.17$ \\
\hline
\end{tabular}

Table 4: Reference intervals of $\mathrm{Hb}$ and PCV in the Iraqi local horses according to sex.

\begin{tabular}{|c|c|c|c|c|c|c|c|c|c|}
\hline Parameter & Unit & Mean & Median & SD & $\begin{array}{c}\text { Lower } \\
\text { limit RI }\end{array}$ & $\mathbf{L L}\left(\mathbf{C I}_{\mathbf{9 0 \%}}\right)$ & $\begin{array}{c}\text { Upper } \\
\text { limit RI }\end{array}$ & $\mathrm{UL}\left(\mathbf{C I}_{90 \%}\right)$ & Method \\
\hline $\mathrm{Hb}$ & $\mathrm{g} / \mathrm{dL}$ & \multirow{2}{*}{10.48} & \multirow{2}{*}{10.3} & \multirow{2}{*}{0.94} & \multirow{2}{*}{8.39} & \multirow{2}{*}{ 7.39-8.91 } & \multirow{2}{*}{12.37} & \multirow{2}{*}{$11.76-12.90$} & \multirow{2}{*}{$\mathrm{R}$} \\
\hline \multicolumn{2}{|c|}{ Male } & & & & & & & & \\
\hline \multicolumn{2}{|c|}{ Female } & 10.01 & 10.2 & 1.23 & 7.2 & $7.20-7.34$ & 12.1 & $11.70-13.00$ & NP \\
\hline PCV & $\%$ & \multirow{2}{*}{28.85} & \multirow{2}{*}{28.4} & \multirow{2}{*}{3.95} & \multirow{2}{*}{22.69} & \multirow{2}{*}{$21.21-24.54$} & \multirow{2}{*}{38.18} & \multirow{2}{*}{$34.66-42.17$} & \multirow{2}{*}{ BCR } \\
\hline \multicolumn{2}{|c|}{ Male } & & & & & & & & \\
\hline \multicolumn{2}{|c|}{ Female } & 27.2 & 28.3 & 4.1 & 17.65 & $17.40-18.74$ & 33.31 & $32.05-33.90$ & NP \\
\hline
\end{tabular}

\section{R=Robust}

$\mathrm{NP}=$ Non-parametric

$B C R=$ Box-Cox Robust

The results of hematological parameters showed that only the PCV and WBC are normally distributed, and the other parameters did not normally distribute. Several researches reported that the blood parameters are most often not normally distributed in animals $[6,19,20]$. Therefore, the appropriate method for estimating the reference interval is the non-parametric method as this method did not need any specific distribution of the data [21]. All references values showed lower width between lower and upper limits as compared with GRI. These results are expected since the values of GRI included different breeds, management, and climates $[6,17]$. Also, results showed the lower limit of RBC, Hb, and PCV was lowered than the lower limit of GRI. The differences between LRI and GRI could be attributed to the adaptation of animals to the harsh environment and the way of breeding. The significant $(\mathrm{P}<0.05)$ differences in the $\mathrm{Hb}$ and PCV due to sex in a current study was agreed with results obtained by Gupta et al. [3], Lana and Tomenendalova et al. [5]. Also, the non-significant effect of age on all parameters was observed in this study which is in the line with the results reported by Lana However, there were some studies showed a significant effect of age on hematological parameters $[3,5,9]$. These differences among studies could be reflecting the difference in the sample size, breed, and climate [22].

\section{CONCLUSION}

The results of the present study confirmed the need of establishing reference values for Iraqi local horses as there was a considerable difference between LRI and GRI ant these differences could be attributed to the adaptation of animals to the harsh environment and the way of breeding.

\section{ACKNOWLEDGMENT}

We would like to acknowledge the assistance of the staff at the College of Veterinary Medicine, University of Baghdad.

\section{CONFLICT OF INTEREST}

The authors declare that they have no conflict of interest.

\section{REFERENCES}

1. Carlos MM, Leite JH, Chaves DF, Vale AM, Façanha DA, et al. (2015) Blood parameters in the Morada Nova sheep: influence of age, sex and body condition score. J Anim Plant Sci 25(4): 950-955.

2. Coskun A, Ceyhan E, Inal TC, Serteser M, Unsal I (2013) The comparison of parametric and nonparametric bootstrap methods for reference 
interval computation in small sample size groups. Accred Qual Assur 18(1): 51-60.

3. Gupta AK, Kumar S, Pal Y (2002) Biochemical, haematological and thyroid hormone profile in healthy Indian Kathiawari horses. AsianAustralas J Anim Sci 15(8): 1215-1221.

4. Pađen L, Gomerčić T, Đuras M, Arbanasić H, Galov A (2014) Hematological and serum biochemical reference values for the Posavina and Croatian coldblood horse breeds. Acta Vet 64(2): 200-212.

5. Tomenendalova J, Vodicka R, Uhrikova I, Doubek J (2014) Determination of haematological and biochemical parameters of Przewalski horses (Equus przewalski) kept by the Prague Zoo. Vet Med 59(1): 11-21.

6. Aros K, Carrasco J, Briones R, Tadich TA (2017) Haematological and serum biochemical reference values for urban-working equines in Chile. Austral J Vet Sci 49(1): 27-33.

7. Pritchard JC, Burn CC, Barr AR, Whay HR (2009) Haematological and serum biochemical reference values for apparently healthy working horses in Pakistan. Res Vet Sci 87(3): 389-395.

8. Satue K, Hernandez A, Muñoz A (2012) Physiological factors in the interpretation of equine hematological profile. In: Charles Lawrie CH(Ed), Hematology-Science and Practice, UK, pp:573-596.

9. Cruz NI, Merino JO, López EA, Monreal AE, Aguirre G, et al. (2017) Effect of age, gender and season on hematological parameters in quarter horses. J Vet Sci Med Diagn 5(6): 2.

10. AL-Hadithy HAH (2011) Assessment of some liver enzyme activities in healthy Iraqi racing Horses. Iraqi J Vet Med 35(1): 76-80.

11. Hasso SA, Al-Hadithy HAH, Hameed RM (2012) Serum glucose concentration and lipid profile in racing horses. Iraqi Journal of Veterinary Sciences 26(1): 1-3

12. Patterson TB, Shrode RR, Kunkel HO, Leighton RE, Rupel IW (1960) Variations in certain blood components of Holstein and Jersey cows and their relationship to daily change in rectal temperature and milk and butter fat production. J Diary Sci 43(9): 1263-1274.
13. (2010) SAS/STAT users guide for personal computer. Release 9.1. mSAS Institute Inc. USA.

14. Constable P, Hinchcliff KW, Done S, Gruenberg W (2016) Veterinary Medicine. A textbook of the diseases of cattle, horses, sheep, pigs and goats-two-volume set. $11^{\text {th }}$ edn. Saunders Ltd, UK.

15. Gordon ME, McKeever KH, Betros CL, Manso-Filho HC (2007) Plasma leptin, ghrelin and adiponectin concentrations in young fitracehorses versus mature unfit standard breeds. Vet J 173(1): 91-100.

16. Luna-Fineman S, Barnoya M, Bonilla M, Fu L, Baez F, et al. (2012) Retinoblastoma in Central America: report from the Central American Association of Pediatric Hematology Oncology (AHOPCA). Pediatr Blood Cancer 58(4): 545-550.

17. Padalino L, Mastromatteo M, Lecce L, Spinelli S, Contò F, et al. (2014) Chemical composition, sensory and cooking quality evaluation of durum wheat spaghetti enriched with pea flour. Int J Food Sci Technol 49(6): 1544-1556.

18. Al-Jbory WA, Al-Samarai FR (2016) Some hematological reference values estimated by the reference values advisor in the Iraqi Awassi sheep. Comp Clin Path 25(6):1155-1162.

19. Al-Samarai FR, Mohammad MH (2017) Estimation of hematological reference intervals for clinically healthy Iraqi local goats using reference value advisor. Comp Clin Path 26(4): 831-836.

20. Cywińska A, Czopowicz M, Witkowski L, Górecka R, Degórski A, et al (2015) Reference intervals for selected hematological and biochemical variables in Hucul horses. Pol J Vet Sci 18(2): 439-445.

21. Geffré A, Concordet D, Braun JP, Trumel C (2011) Reference value advisor: a new freeware set of macroinstructions to calculate reference intervals with Microsoft Excel. Vet Clin Pathol 40(1): 107-112.

22. Tadic-Galeb B, Fischer RE, Kappel D, Condra NL, Muscato AM, et al (2001) Inventors; Compaq Computer Corp, assignee. Projection lens and system. United States patent, USA, 6: 220-713. 